Annales Geophysicae (2001) 19: 855-861 C European Geophysical Society 2001

\title{
Estimation of temperature and humidity from MST radar observations
}

\author{
K. Mohan ${ }^{1}$, D. Narayana Rao ${ }^{1}$, T. Narayana Rao ${ }^{1}$, and S. Raghavan ${ }^{2}$ \\ ${ }^{1}$ Department of physics, Sri Venkateswara University, Tirupati-517 502, India \\ ${ }^{2}$ Ex-IMD, Chennai, India
}

Received: 28 August 2000 - Revised: 19 May 2001 - Accepted: 6 June 2001

\begin{abstract}
Retrieval of vertical profiles of temperature and humidity parameters using a VHF radar is described in this paper. For this, Indian MST radar located at Gadanki $\left(13.5^{\circ} \mathrm{N}, 79.2^{\circ} \mathrm{E}\right)$ has been operated in a special mode. First, vertical velocities are collected continuously using the radar and are subjected to Fast Fourier Transform (FFT) analysis to obtain Brunt-Väisälä oscillations. From the measured BruntVäisälä oscillations, temperature profile is obtained from the radar observations following Revathy et al. (1996). The various terms required for the retrieval of vertical profiles of humidity are the eddy dissipation rate, $\varepsilon$, the volume reflectivity, $\eta$, and the potential refractive index gradient, $M$. The eddy dissipation rate, $\varepsilon$, is calculated from the spectral width after removing the effects due to non-turbulence. The volume reflectivity, $\eta$, of the turbulence scattering is calculated using the signal-to-noise ratio as a function of height. The potential refractive index gradient, $M$, is evaluated using the measured Brunt-Väisälä oscillations, the eddy dissipation rate and the volume reflectivity, $\eta$. Vertical profiles of humidity are retrieved following Tsuda (1997) using the radar derived temperature as well as the balloon measured temperature and are compared with the humidity as measured by the radiosonde. The sign of the potential refractive index gradient, $M$, is taken from the simultaneous measurements of balloon soundings. The retrieved vertical profiles of temperature and humidity have been compared with the radiosonde data, which are released simultaneously with the radar observations at the radar site. A fairly good comparison is seen between the two measurements on some days and there are some discrepancies on some other days. The strengths and limitations in estimating the vertical profiles of temperature and humidity from the radar observations are discussed.
\end{abstract}

Key words. Atmospheric composition and structure (pressure, density and temperature; enhancements and techniques)

Correspondence to: D. Narayana Rao (profdnrao@usa.net)

\section{Introduction}

The temperature, wind and humidity are the key parameters in understanding the various dynamical processes in the atmosphere. Since the standard balloons do not have the adequate spatial and temporal resolutions needed to study the mesoscale phenomena, the pulsed Doppler radars have the advantage of being able to study the mesoscale dynamics of the atmosphere due to their good spatial and temporal resolutions. Radar backscattering from the turbulent, clear atmosphere is determined by the small-scale variability in the refractive index fluctuations, $\Delta n$, of the air which result from the turbulent mixing of humidity and temperature. The refractive index at microwave frequencies depends primarily on temperature and humidity (Bean and Dutton, 1966) in the lower atmosphere. The backscattered radar echoes are not only due to the Bragg scattering from the small-scale irregularities of the refractive index fluctuations, but also contributions from the non-turbulent scatter (Fresnel scatter) or scattering from anisotropic turbulence. These radars are also sensitive to scattering particles (precipitation). These scattering mechanisms (Bragg, Fresnel and Raleigh) have been studied by some of the investigators (Booker and Gorden, 1950; Chisholm et al., 1955; Probert-Jones, 1962; Lane and Sollum, 1965; Hardy et al., 1966; Kropfli et al., 1968; Lane, 1969; Belrose, 1970; Evans, 1974; Gage and Green, 1978; Röttger and Liu, 1978; Fukao et al., 1978; Röttger and Vincent, 1978) from the observed radar echo power. Moreover, the contribution of water vapour to $n$ is more for radio waves than for optical frequencies (Battan, 1973), particularly in the lower atmosphere up to $10 \mathrm{~km}$. Although the Doppler radars are primarily used to sense the wind field and its associated turbulence parameters by making use of radar with the combination of the Radio Acoustic Sounding System, (RASS) temperature can be derived with good spatial and temporal resolutions (Mathura et al., 1986). This RASS technique is one of the most powerful techniques to monitor temperature with good time and height resolutions in the troposphere and lower stratosphere (Tsuda et al., 1989). Temperature can 
also be derived from the radar vertical velocities under undisturbed weather conditions. The concept of deriving temperature from the radar vertical velocities primarily depends upon the identification of the Brunt-Väisälä frequency in the spectra of vertical wind velocity oscillations. The BruntVäisälä frequency can be characterized by a spectral peak at the Brunt-Väisälä frequency with a steep decrease on its high frequency side and a shallow decrease on the low frequency side (Rastogi, 1975; Röttger, 1980a, 1980b; Ecklund et al., 1985). Making use of Röttger's (1984) method, Revathy et al. (1996) had derived temperature from the observed radar vertical velocities by identifying the Brunt-Väisälä frequencies.

Since the wind and temperature are derivable from the radar observations and there is no direct method to measure humidity from the radar observations, Stankov et al. (1996) used a coupled statistical and physical retrieval technique to obtain humidity by combining the data from ground-based instruments, such as RASS, Lidar, Celiometers and satellite (microwave radiometers) measurements. The same methodology is also used by Gossard et al. (1999) to retrieve the profiles of the refractive index gradients, as well as humidity from the combined measurements of ground-based radar, RASS and Global Positioning Systems (GPS). But Tsuda (1997) proposed a technique to retrieve the humidity from the combined observations of radar and RASS. Low and Tsuda (1997) extended this work through the addition of simultaneous RASS temperature measurements and the consideration variable radar echo power characteristics. In the present study we use the following methodologies of Revathy et al. (1996) and Tsuda (1997) for temperature and humidity respectively. The main theme of this paper is to understand the capability of the radar in deriving the meteorological parameters, such as temperature and humidity. The system description, experimental specifications and the data used for the present study are explained in Sect. 2. The methodology and results are given in Sect. 3. The summary and conclusions are given in Sect. 4.

\section{System description and data base}

The Indian Mesosphere-Stratosphere-Troposphere (MST) radar, located at Gadanki $\left(13.5^{\circ} \mathrm{N}, 79.2^{\circ} \mathrm{E}\right)$, is a pulse coded coherent VHF phased array radar operating at $53 \mathrm{MHz}$ with an average power aperture product of $7 \times 10^{8} \mathrm{Wm}^{2}$. It consists of 1024 crossed three-element Yagi antennas which occupy an area of $130 \mathrm{~m} \times 130 \mathrm{~m}$ and generate a radiation pattern with a beam width of $3^{\circ}$ and a gain of $36 \mathrm{~dB}$. The peaktransmitted power of this radar is $2.5 \mathrm{MW}$. A complete system description of the radar is given by Rao et al. (1995) and Kishore (1995).

Radar is operated in a special mode to retrieve temperature and humidity parameters with the Indian MST radar from 19 July 1999 to 14 August 1999 for about four hours from 1600-2000 local time (LT). During the observation period, balloons were launched from the radar site at 1630 LT. In this experiment, the radar is operated in two modes. In the first mode, the radar is pointed in six directions (east $10^{\circ}$, west $10^{\circ}$, north $10^{\circ}$, south $10^{\circ}$ and $Z_{x}, Z_{y}$ are in vertical direction in east-west and north-south polarization, respectively). This data is used not only to obtain the background wind information, but also to extract the humidity profile. In the other mode, only the vertical beam is used to obtain the BruntVäisälä oscillations for the temperature evaluation. In both modes, the radar is operated with 128 FFT points, $256 \mathrm{co}-$ herent integrations, one incoherent integration, $1000 \mu \mathrm{s}$ IPP and a $16 \mu$ s-coded pulse.

\section{Methodology and results}

Röttger (1986) proposed a method to identify the BruntVäisälä oscillations from the vertical winds, consequently followed by Revathy et al. (1996) and Rao et al. (1998). The Brunt-Väisälä frequency is the displacement of a vertically oscillating air parcel in a convectively stable fluid layer from its equilibrium position. They have identified a spectral peak at the Brunt-Väisälä frequency in the power spectrum when that peak in the spectrum shows a steep gradient on its high frequency side and a shallow decrease on its low frequency side. We have also adopted the same methodology to identify the Brunt-Väisälä oscillations from the Indian MST radar measured vertical winds. The radar is operated for about one hour and thirty minutes in temperature mode, using a vertical beam with a time resolution of $46 \mathrm{~s}$ to identify the Brunt-Väisälä frequencies from the vertical velocities. A Fast Fourier Transformation (FFT) algorithm has been applied to the observed vertical velocities in order to identify the Brunt-Väisälä frequencies. Figure 1 shows a typical identification of a Brunt-Väisälä frequency from the spectra of vertical wind velocity. Figures $2 a$ and $2 b$ show the vertical profiles of the Brunt-Väisälä frequencies of the radar (solid line) and radiosonde (line with circles) in two different conditions on 20 July and 19 July 1999, respectively. Figure 2a shows the vertical profile of the BruntVäisälä frequencies drawn on fair weather conditions (clear sky/calm atmosphere) and Fig. 2b shows the vertical profiles of the Brunt-Väisälä frequencies drawn on disturbed weather conditions(cloudy/ovsercast sky). In Fig. 2a, the identified Brunt-Väisälä frequencies match fairly well with the radiosonde measured Brunt-Väisälä frequencies on a fair weather day. But there is some discrepancy on the cloudy day, i.e. in Fig. 2b. From this figure, it is also noted that the Brunt-Väisälä frequencies are, in general, higher in the stratosphere than in the troposphere, and they are in the range of $0.01 \mathrm{rad} / \mathrm{sec}$ in the troposphere and $0.022 \mathrm{rad} / \mathrm{sec}$ in the lower stratosphere.

The observed Brunt-Väisälä frequencies from the radar vertical velocities may have effects due to atmospheric gravity waves (Fritts and VanZandt, 1987; Vincent and Eckermen, 1990). The effect of Doppler shifting due to atmospheric gravity waves is calculated according to Fritts and VanZandt (1987) with the following procedure. The normal- 


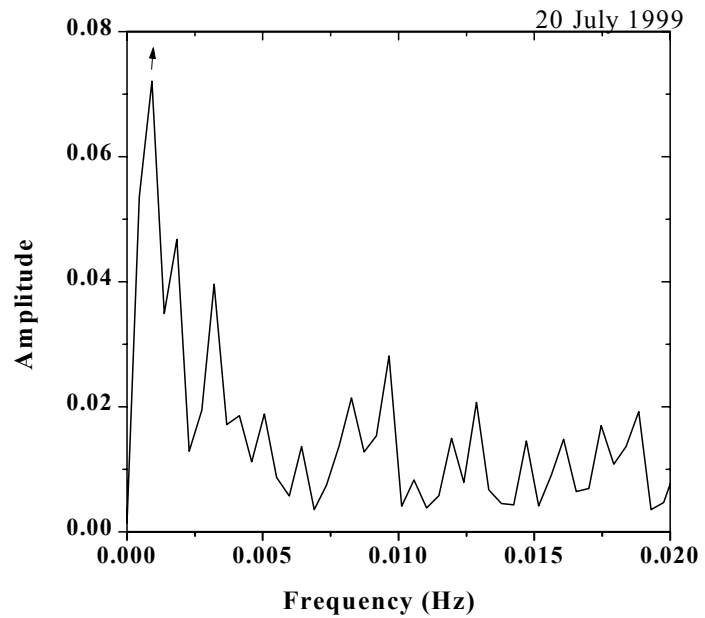

Fig. 1. A typical plot showing the identification of the BruntVäisälä frequency from the radar vertical velocities using the Fast Fourier Transform analysis technique from the spectra of vertical velocities at a $10.2 \mathrm{~km}$ height taken on 20 July 1999 . The arrow in the figure shows the Brunt-Väisälä frequency at that height.

ized energy spectrum corresponds to a monochromatic wave motion at intrinsic frequency $\omega^{1}=\omega_{0}^{1}$ with the horizontal wave number $\boldsymbol{k}=\boldsymbol{k}_{0}$. This is given by

$E\left(\boldsymbol{k}, \omega^{1}\right)=\delta\left(\boldsymbol{k}-\boldsymbol{k}^{0}\right) \delta\left(\omega^{1}-\omega_{0}^{1}\right)$

where the $\delta$ s are direct delta functions. The consequences of the Doppler shifting of this spectrum are, of course, trivial. If the wave motion occurs in an environment with a mean wind $\bar{u}$ normal to the horizontal intrinsic phase velocity of the wave, of magnitude $c_{0}^{1}=\boldsymbol{k}_{0} \omega_{0}^{1} / k_{0}^{2}$, the frequency is seen by the observer at rest remains unaltered. However, if the mean motion has a component in the direction of the wave propagation, the observed frequency is given by

$$
\begin{aligned}
\omega & =\omega^{1}+\boldsymbol{k} \cdot \overline{\boldsymbol{u}}=\omega_{0}^{1}+k_{0} \bar{u} \cos \varphi \\
& =\omega_{0}^{1}\left(1+\frac{\bar{u} \cos \varphi}{c_{0}^{1}}\right)=\omega_{0}^{1}\left(1+\beta_{0} \cos \varphi\right)
\end{aligned}
$$

where $k_{0}$ is the (positive) magnitude of $\boldsymbol{k}, \varphi$ is the angle between the horizontal wind components of $\boldsymbol{k}$ and $\overline{\boldsymbol{u}}$, and $\beta_{0}=\bar{u}_{0} / c_{0}^{1}$ is the scaled mean wind. The fractional frequency shift is given by

$\frac{\omega-\omega_{0}^{1}}{\omega_{0}^{1}}=\beta_{0} \cos \varphi$

The quantity $\beta_{0} \cos \varphi$ thus provides a convenient measure of the effects of Doppler shifting on the frequency spectra of the observed wave motions. The Doppler correction of $0.01 \mathrm{~Hz}$ is needed. The $\beta_{0}$ is as large as $0.015 \mathrm{~Hz}$. The Doppler corrected Brunt-Väisälä frequencies are used to derive the temperature profile from the MST radar following the methodology of Revathy et al. (1996) and the temperature at each

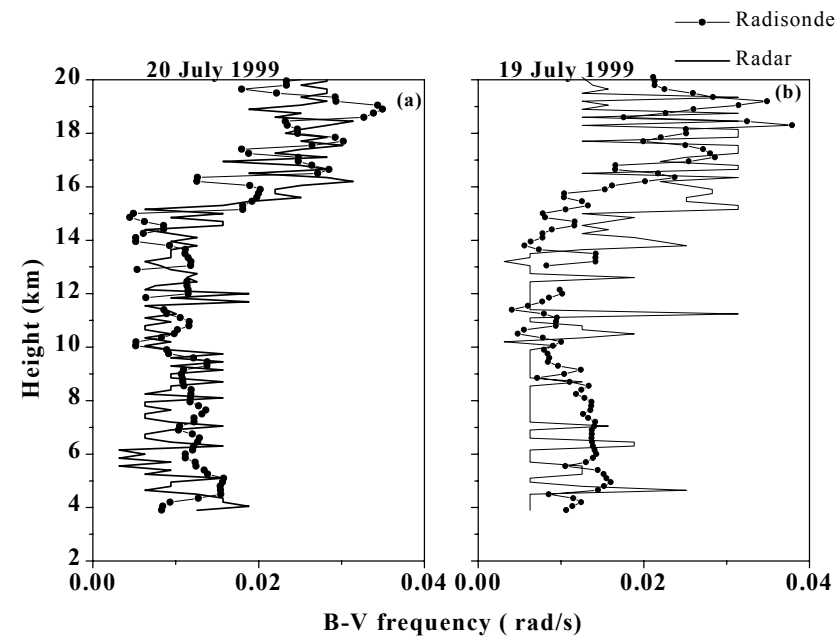

Fig. 2. Comparison of identified radar Brunt-Väisälä frequencies from the radar vertical velocities with the calculated Brunt-Väisälä frequencies from the radiosonde (a) on a clear day (20 July 1999) and (b) on a cloudy day (19 July 1999).

altitude $Z$ is estimated as

$T\left(Z^{*}\right)=\frac{1}{I(Z)}\left[I\left(Z_{0}\right) T_{0}-\Gamma \int_{Z_{\max }}^{Z} I(Z) d z\right]$

where

$I(Z)=\exp \left[-\int\left(\frac{N^{2}}{g}\right) d z\right]$

where $N$ is the Brunt-Väisälä frequency in $\mathrm{rad} / \mathrm{sec}, g$ is the acceleration due to gravity, $Z$ is the altitude, $\Gamma$ is the dry adiabatic lapse rate and $T_{0}$ is the reference temperature taken from the balloon measurements. Using Eq. (4), temperature profiles are derived for all the days during the observation period. Figures $3 \mathrm{a}$ and $3 \mathrm{~b}$ show a typical profile of the radar derived (solid) and radiosonde measured (line with circles) temperature for different conditions. From Fig. 3a, it is clear that the radar derived temperature matches fairly well with the radiosonde measured profile on fair weather days. In meteorological convention there is a cloud free atmosphere on these days. In Fig. 3b, there is some discrepancy in temperature between the radar derived and the radiosonde measured profiles. This discrepancy is due to the difficulty in the identification of Brunt-Väisälä frequencies due to a cloudy atmosphere during the operation time. Moreover, the temperature measured by the radiosonde is the point observation, whereas radar derived temperature is an integrated profile over a period of time. Therefore, this discrepancy in the temperature between radar and radiosonde is expected and depending on weather conditions, it varies from the radar by $2-3 \mathrm{~K}$ and is reasonable. Figure 4 shows a comparison of radar derived temperatures with the radiosonde measured temperature on different days during the campaign period. 


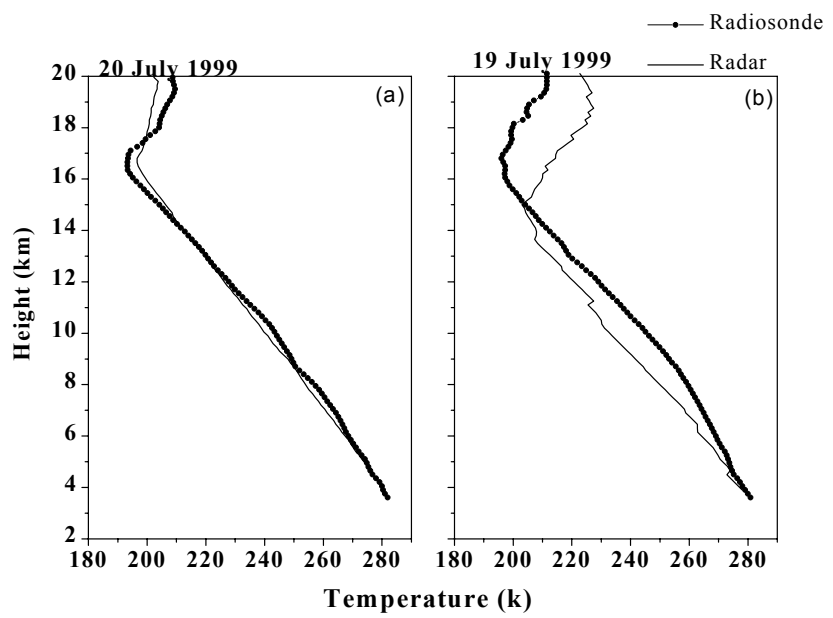

Fig. 3. Comparison of radar derived temperature profiles with radiosonde measured temperatures profiles (a) on a clear day (20 July 1999) and (b) on a cloudy day (19 July 1999).

When the radar derived temperature profile matches fairly with the radiosonde profile, it is identified with a label (a) for clear sky days, with a label (b) for partly cloudy days and with a label (c) for cloudy days. The standard deviation for clear air days is around $1-2 \mathrm{~K}$ in the troposphere and $2-3 \mathrm{~K}$ in the stratosphere with the regression coefficient of 0.995 . The standard deviation for cloudy and partly cloudy days is around $2-4 \mathrm{~K}$ in the troposphere and $5-6 \mathrm{~K}$ in the stratosphere with the regression coefficient of 0.98 .

The humidity profile is extracted from the radar derived temperature and also by using the radiosonde measured temperature as outlined by Tsuda (1997) and is as follows. The well-known equation for the potential refractive index gradient, $M$, is given (Otterson, 1969) as

$$
\begin{aligned}
M=-77.6 \times 10^{-6} \frac{P}{T}\left[\frac{N^{2}}{g}+15\right. & 600\left(\frac{q N^{2}}{T g}\right) \\
& \left.-\frac{7800}{T}\left(\frac{d q}{d z}\right)\right]
\end{aligned}
$$

where $P$ is the pressure, $T$ is the temperature, $N$ is the BruntVäisälä frequency and $q$ is the specific humidity. The first term in the bracket is the dry term and it depends on temperature. The other two terms are wet terms and they depend on $q$ and $(d q / d z)$, respectively. The specific humidity gradient term, which is the third term in the bracket, plays a key role in the lower troposphere up to $10 \mathrm{~km}$. The dry term dominates the upper troposphere where humidity concentrations are less. The refractive index gradient, $M$, is related to the volume reflectivity, $\eta$, of the turbulence scattering as

$\eta=C \epsilon^{2 / 3} M^{2} N^{-2}$

where $N$, the Brunt-Väisälä frequency. $\epsilon$ is the turbulence eddy dissipation rate and it is estimated from the width of the Doppler spectrum after removing all contributions to the spectral width except turbulence (Cohn, 1995; Fukao et al., 1994 and Nastrom and Eaton, 1997). $C$ is a constant and it depends on radar parameters. Equation (6) is appropriate only for the turbulence scattering and is not suitable for the scattering due to anisotropic turbulence or scattering due to precipitation particles. Such data is not used to derive the refractive index gradient, $M$, from the radar. The turbulence eddy dissipation rate is estimated from the spectral width of oblique beams using the relation

$\epsilon=A^{-1 / 3} \sigma_{\text {turb }}^{2} N^{-1}$

where $A=1.6$ is a constant. By knowing $N, \eta, \epsilon$ and $C, M$ can be evaluated using Eq. (6). The sign of the refractive index gradient, $M$, is generally negative except at cloud boundaries. Since we don't have any instrument, such as a celiometer to detect the cloud boundaries, the sign of $M$ is taken from the corresponding radiosonde measurements. The contribution of the absolute humidity term to the refractive index gradient, $M$, is less in the planetary boundary layer compared to other terms; above that, it is negligible. The contributions of the three terms to $M$ are also checked by using one year of meteorological data obtained from the nearest India Meteorological Department (IMD) radiosonde observations. From the study it is determined that the contribution of the specific humidity to the refractive index gradient, $M$, is less in the boundary layer up to $5 \mathrm{~km}$ and above that, it is negligible. Therefore, after removing the specific humidity term from Eq. (5), and rearranging and integrating the equation, it can be expressed in $Q(z)$ as

$$
\begin{aligned}
Q(z) & =Q_{Z_{\mathrm{ref}}}+1.65 \\
& \int_{Z_{\max }}^{Z}\left(\frac{T^{2} M}{P}\right) d Z+\frac{1}{7800}\left(T+\Gamma_{Z}\right)_{Z_{\max }}^{Z}
\end{aligned}
$$

where $T$ is the temperature, $P, Q_{Z_{\text {ref }}}$ are the pressure and reference humidity, respectively, and are taken from the balloon soundings. $\Gamma_{Z}$ is taken from the model atmosphere, $Z$ and $Z_{\max }$ are the initial and final limits of the interval. By using Eq. (8), the humidity profile is extracted from the radar derived temperature (RDT), as well as radiosonde measured temperature (RST) and they are compared to the humidity as given by the radiosonde (RSW). A typical comparison of the humidity profile is shown in Figs. 5a and 5b. From Fig. 5, it is also noted that the radar derived humidity profiles RDT and RST both have higher values than the humidity as measured by radiosonde (RSW). The humidity profiles derived using the radiosonde measured temperature match fairly well with the humidity as measured by the radiosonde, and the discrepancies (if any) in these profiles may be due to the magnitude difference of the refractive index gradient, $M$, and the sign of the refractive index gradient. The humidity profiles derived using the radar derived temperature (RDT) have some large discrepancies compared to the humidity derived using the radiosonde measured temperature (RST), and these discrepancies are due to the temperature differences and also due to the magnitude difference in the refractive index gradient, $M$. 

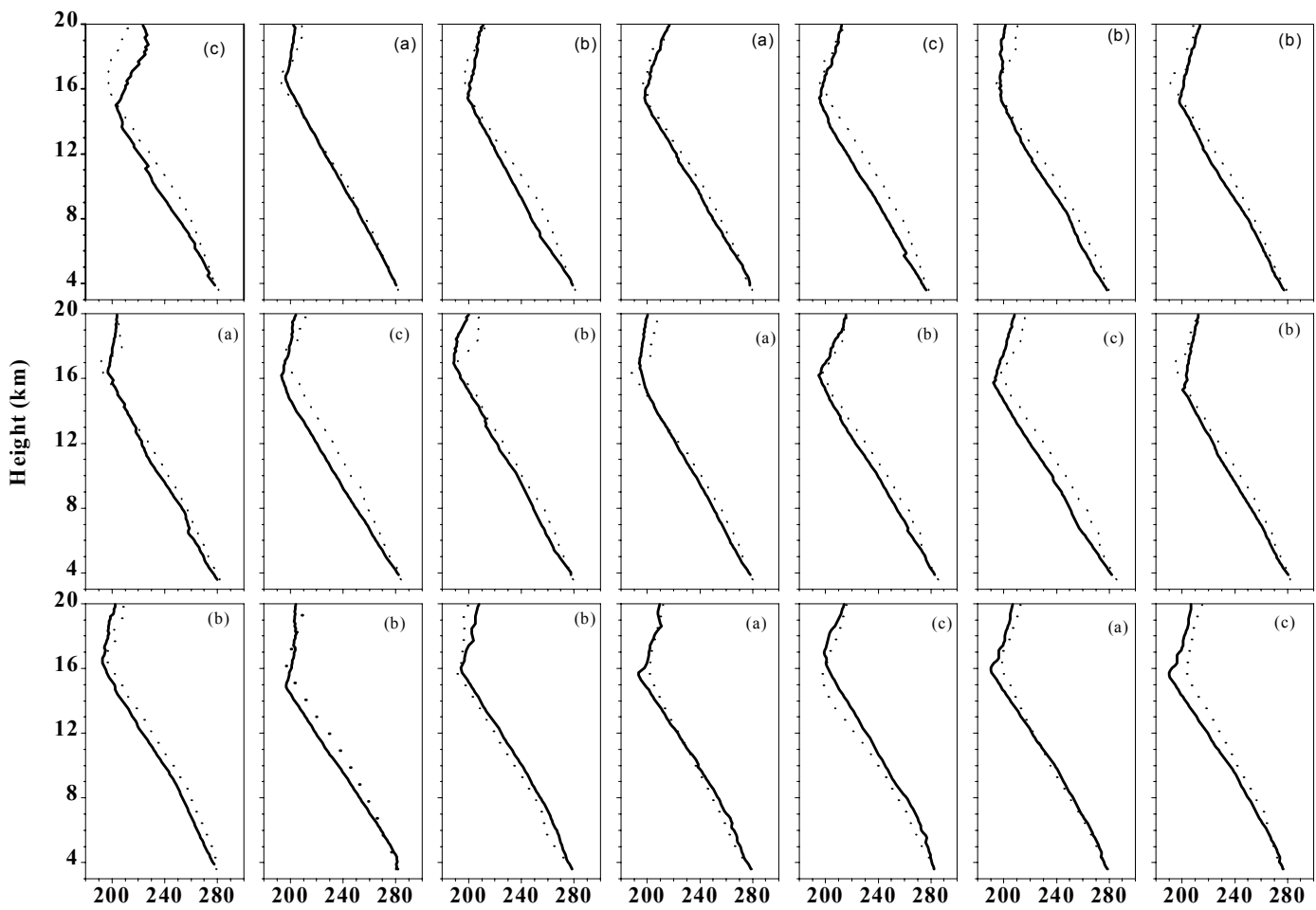

Temperature (K)

Fig. 4. Comparison of radar derived temperature profiles with radiosonde measured temperature profiles during the radar-radiosonde campaign period during July-August 1999. The solid lines correspond to radar derived temperature profiles and dashed lines correspond to radiosonde measured temperature profiles. The labels indicate (a) clear (b) partly cloudy and (c) cloudy.

In Fig. 5, the line with circles corresponds to the humidity as given by the radiosonde, and the solid lines and downward sloping triangles correspond to the humidity derived using radar derived temperature and radiosonde measured temperature, respectively. In all cases, the humidity extracted using the radiosonde temperature matches closer with the humidity, as given by the radiosonde, than with the humidity extracted from the radar derived temperature. Figure 6 shows the humidity profiles derived from the radar during the campaign period. On some of the days, the radar derived humidity profiles are matching fairly well with the humidity as measured by the radiosonde, denoted by (a), and these discrepancies are due to the magnitude difference in the refractive index gradient, $M$. Other days, labeled with (b) and (c), have large discrepancies due to the magnitude difference and the sign of the refractive index gradients.

\section{Summary and conclusions}

A special experiment is conducted to retrieve the temperature and humidity profiles from the Indian MST radar observations alone. These profiles are compared with the simultaneously launched radiosonde flights at the radar site. A fairly good agreement in temperature is found between the two measurements on clear air days and there are some dis-

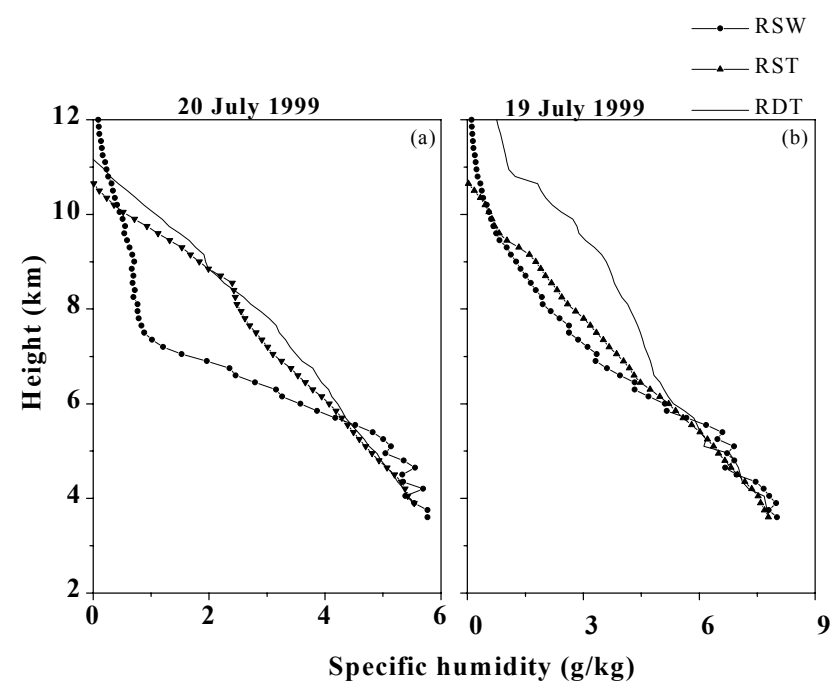

Fig. 5. Comparison of radar derived humidity profiles using radar derived temperature (RDT) and radiosonde measured temperature (RST) profiles with the humidity as measured by radio sonde (RSW) on (a) on a clear day (20 July 1999) and (b) on a cloudy day (19 July 1999).

crepancies on partly cloudy and cloudy days. The humidity profiles derived from the radar using RDT and RST match fairly well with the humidity as measured by the radiosonde, 


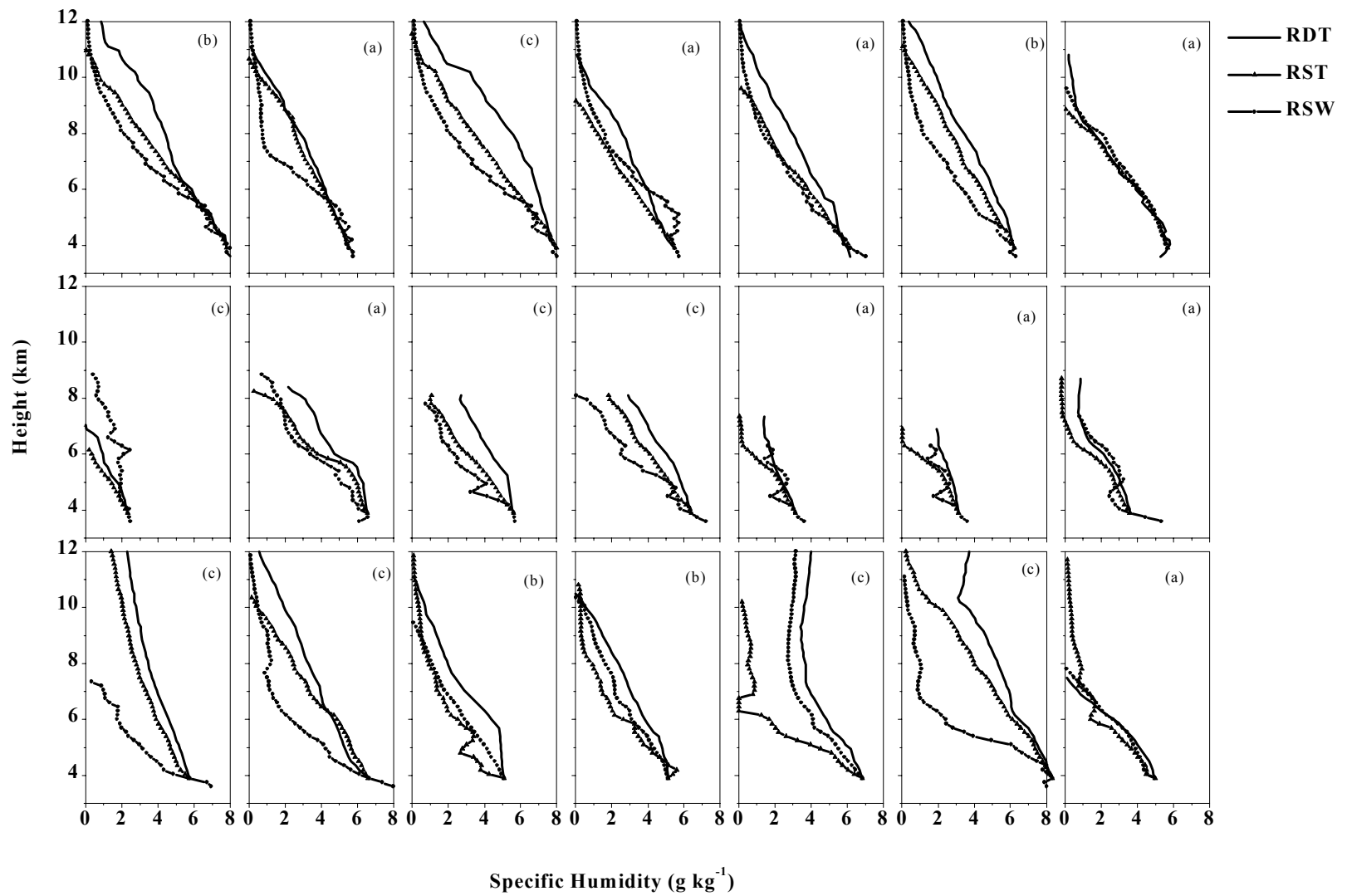

Fig. 6. Comparison of radar derived humidity profiles using radar derived temperature (RDT) with solid lines, radiosonde measured temperature (RST) profiles with downward sloping triangles and the humidity as measured by the radiosonde (RSW) with circles during the radar-radiosonde campaign period during July-August 1999. The labels indicate (a) clear (b) partly cloudy and (c) cloudy.

and on these days, the refractive index gradients measured from the radar are in good agreement with the radiosonde. On some other days, there are discrepancies in the measured humidity profiles, which may be due to the discrepancies in the refractive index gradient and the temperature. Although the temperature and humidity profiles match fairly well on some of the days with the radiosonde measured values, there are still some limitations in this method. First, the identification of the Brunt-Väisälä frequency from the disturbed atmospheric condition, i.e. events such as convection, precipitation etc. are very difficult. Therefore, the temperature estimation is only possible in calm and stable atmospheric conditions. Second, the specific humidity term is not considered while deriving the humidity profile. The contribution of the specific humidity term is less above $5 \mathrm{~km}$ and can be neglected. But below $5 \mathrm{~km}$, the contribution of $q$ cannot be neglected. Third, the constant $C$ depends primarily on the radar parameters, so one has to calibrate the radar parameters to obtain a good refractive index profile. Fourth, knowing the sign of $M$ is not possible from the MST radar observations. Gossard et al. (1999) stressed the importance of the sign of the potential refractive index gradients in retrieving the humidity profile. But in the present study, the sign of $M$ is taken from simultaneous radiosonde measurements.
On most of the occasions, the radar derived humidity shows higher values than the radiosonde derived humidity observations. This kind of discrepancy is also observed by several other investigators (Tsuda, 1997; Gossard et al., 1999). In spite of all these limitations, the agreement between the radar and radiosonde measured values of temperature and humidity shows the capability of the radar in deriving temperature and humidity. From the results, it is concluded that the radar can be used to study temperature and humidity under appropriate conditions. Efforts are still going on to reduce the limitations in estimating the temperature and humidity from the radar technique itself.

Acknowledgements. The National MST Radar Facility (NMRF) has been set up jointly by the Council of Scientific and Industrial Research, the Defence Research and Development Organization, the Department of Environment, and the Department of Space of the government of India.The authors are thankful to UGC-SVU Center for MST Radar Applications, S. V. University, Tirupati for providing the necessary facilities to carry out the research work. Authors express their gratitude to National MST Radar Facility (NMRF) in providing the data. The ready help of our software team, Mr. M. V. M. Kumar, Miss. E. C. Jayasree and Mr. S. C. Mouli are greatefully acknowledged.

Topical Editor J.-P. Duvel thanks two refereees for their help in evaluating this paper. 


\section{References}

Battan, L. J., Radar observations of the Atmosphere, The University of Chicago press, Chicago, 1973.

Bean, B. R. and Dutton, E. J., Radar meteorology, National Bureau of Standards monogr., No. 92, U. S. Govt. Printing Office, pp 435, 1966

Belrose, E. J., Radio wave probing of the ionosphere by the partial reflection of radio waves (from heights below $100 \mathrm{~km}$ ), J. Atmos. Terr. Phys., 32, 567-596, 1970.

Booker, H. G. and Gordon, W. E., Theory of radio scattering in the troposphere, Proc. IEEE, 38, 401-412, 1950.

Chisholm, J. H., Portmann, P. A., Debettencourt, J. T., and Roche, J. F., Investigations of angular scattering and multipath properties of tropospheric propagation of short radio waves beyond the horizon, Proc. IEEE, 43, 1317-1335, 1955.

Cohn, A. S., Radar measurements of turbulent eddy dissipation rate in the troposphere: A comparison of techniques, J. Atmos. Oceanic Tech., 12, 85-95, 1995.

Ecklund, W. L., Balsely, B. B., Carter, D. A., Riddle, A. C., Crochet, M., and Garello, R., Observations of vertical motions in the troposphere and stratosphere using three closely spaced S-T radars, Radio Sci., 20, 1196-1206, 1985.

Evans, J. V., Some post-war developments in ground based radio wave sounding of the ionosphere, J. Atmos. Terr. Phys., 36, 2183-2234, 1974.

Fritts, D. and Vanzandt, T. E., Effects of Doppler shifting on the frequency spectra of gravity wave, J. Geophys. Res., 92, 97239732, 1987.

Fukao, S., Kato, S., Yokoi, S., Harper, R. M., Woodman, R. F., and Gordon, W. E., One full day radar measurements of the lower stratosphere winds over Jicamarca, J. Atmos. Terr. Phys., 40, 1331-1337, 1978.

Fukao, S., Yamanaka, M. D., Ao, N., Hocking, W. K., Sato, T., Yamamoto, M., Tsuda, T., and Kato, S., Seasonal variability of vertical eddy diffusivity in the middle atmosphere. Three-year observations by the Middle and Upper atmosphere Radar, J. Geophy. Res., 99, D9, 18 973-18 987, 1994.

Gage, K. S. and Green, J. L., Evidence for specular reflection from monostatic VHF radar observations of the atmosphere, Radio Sci., 13, 991-1001, 1978.

Gossard, I. E., Gutman, S., Stankov, B. B., and Wolf, D., Profiles of refractive in index and humidity derived from radar wind profilers and Global Positioning Systems, Radio Sci., 34, 2, 371-383, 1999.

Hardy, K. R., Atlas, D., and Glover, K. M., Multiwavelength backscatter from the clear atmosphere, J. Geophys. Res., 71, 1537-1553, 1966.

Kishore, P., Atmospheric studies using Indian MST radar winds and turbulence parameters, Ph. D. Thesis. Sri Venkateswara University, Tirupati, India, 1995.

Kropfli, R. A., Katz, I., Konrad, T. G., and Dobson, E. B., Simultaneous radar reflectivity measurements and refractive index spectra in the clear atmosphere, Radio Sci., 3, 991-994, 1968.

Lane, J. A. and Sollum, P. W., VHF transmission over distances of $140 \mathrm{~km}$ and $300 \mathrm{~km}$. Proc., IEEE, London, 112, 254-258, 1965.

Lane, J. A., Radar echoes from the clear air in relation to refractive index variations in the troposphere, Proc. IEEE, London, 116, 1656-1660, 1969.
Low, J. D. and Tsuda, T., Estimating water content profiles with Radar-RASS, Proc. 8th International workshop on technical and scientific aspects of MST radar, Bangalore, 1997.

Matuura, N., Masuda, Y., Inuki, H., Kato, S., Fukao, S., Sato, T., and Tsuda, T., Radio acoustic measurements of temperature profiles in the troposphere and stratosphere, Nature, 323, 426-428, 1986.

Nastrom, G. D. and Eaton, F. D., A brief climatology of eddy diffusivity over white sands missile range, New Mexico, J. Geophys. Res., 102, 29 819-29 826, 1997.

Otterson, H., Mean vertical gradient of potential refractive index in turbulent mixing and radar detection of C.A.T., Radio Sci., 4, 1247, 1969.

Probert-Jones, J. R., The radar equation in meteorology, Q. J. R Meteorol. Soc., 88, 485-495, 1962.

Rao, N. D., Mohan, K., Rao, T. N., and Chandrika, A. Y., Retrieval of humidity profile from radar observations, 32nd Scientific COSPAR Assembly, Nagoya, Japan, 1998.

Rao, P. B., Jain, A. R., Kishore, P., Balamuralidhar, P., Damle, S. H., and Viswanadhan, G., Indian MST radar Part 1. System description and sample vector wind measurements in S.T. mode, Radio Sci., 30, 1125, 1995.

Rastogi, P. K., Remote sensing of the mesosphere using Jicamarca incoherent scatter radar, Aeronomy report. No. 68, Dept. of Elec. Eng. University of Illinois, IL, USA, 1975.

Revathy, K., Nair, S. R. P., and Murthy, B. V. K., Deduction of Temperature profile from MST radar observations of vertical wind, Geophy Res. Lett., 23, 285-288, 1996.

Röttger, J., structure and dynamics of the stratosphere and mesosphere revealed by VHF radar investigations, PAGEOPH, 118, 494-527, 1980a.

Röttger, J., Development of refractivity structures during anticyclone weather conditions, Preprint volume, 19th AMS conf. Radar Meteorology, Miami, FL. USA, 593-598, 1980b.

Röttger, J., Determination of Brunt-Väisälä frequency from vertical velocity spectra, MAP Handbook 20, 168-172, 1986.

Röttger, J. and Liu, C. H., Partial reflection and scattering of VHF radar signals from the clear atmosphere, Geophys. Res. Lett., 5, 357-360, 1978.

Röttger, J. and Vincent, R. A., VHF radar studies of tropospheric velocities and irregularities using spaced antenna techniques, Geophys. Res. Lett., 5, 917-920, 1978.

Stankov, B. B., Westwater, E. R., and Gossard, E. E., Use of wind profiler estimates of significant moisture gradients to improve humidity profile retrieval, J. Atmos. Oceanic. Tech., 13, 1285 , 1996.

Tsuda, T., Estimation of humidity profile from clear air echo characteristics, 8th International workshop on technical and scientific aspects of MST radar, Bangalore, India, 1997.

Tsuda., T., Matsuda, Y., Inuki, H., Takahashi, K., Takami, T., Sato, T., Fukao, S., and Kato, S., High time resolution monitoring of tropospheric temperature with a radio acoustic sounding system (RASS), Pure and Appl. Geophys., 130, 497-507, 1989.

Tsuda, T., Adachi, T., Masuda, Y., , Fukao, S., and Kato, S., Observations of tropospheric fluctuations with the MU Radar and RASS, J. Atmos. Oceanic Tech., 11, 50-62, 1994.

Vincent, R. A. and Eckerman, S. D., VHF radar observations of mesoscale motions in troposphere: Evidence for gravity wave Doppler shifting, Radio Sci., 25, 1019-1037, 1990. 